\title{
MANAJEMEN KURIKULUM PAUD DI LINGKUNGAN PESANTREN (ANALISIS DI TAMAN KANAK-KANAK ISLAM AL ITTIFAQIAH INDRALAYA SUMATERA SELATAN)
}

\author{
Muharrahman \\ STIT Al Qur'an Al Ittifaqiah (STITQI) Ogan Ilir Sumatera Selatan \\ Email: Muharrahman279@gmail.com
}

\begin{abstract}
This research is a qualitative research with phenomenological approach in TAKIAH Indralaya. The purpose of this research is to know: 1) how the implementation of curriculum management of early childhood education based on Islamic Boarding School in TAKIAH; 2) the extent of the involvement of foundations, teachers, parents and the surrounding community in designing and planning curriculum of early childhood education based on Islamic Boarding School in TAKIAH; 3) what problems and solutions faced in curriculum management of Islamic Boarding School-based early childhood education in TAKIAH. Technique of collecting data in this research is observation, documentation, and interview. The results of this study indicate that the implementation of curriculum based on Islamic boarding schools in TAKIAH Indralaya include: 1) Planning, which includes: Prota, Prosem, RKM, and RKH. 2) Implementation. a) Religious activities, including: Memorize daily prayer and short letters of Qur'an, dhuha Prayers, Watching religious cartoons, Manasik Hajj, and basic Arabic. b) Common knowledge and art, including: Introduction of traffic signs, creating communication devices (telephones), and dancing. 3) Monitoring. a) School supervision of the foundation, including: School observation, Group meetings, and individual Talks. b) School principal supervision to teachers, including: Practice (demonstration) teaching, Class observation, Individual talks, and Group meetings. 4) Evaluation. Implemented at the end of every year of the lesson by CIPP evaluation model, which includes: context, input (children, educators, and infrastructure), process, and output. The design and planning of the curriculum involves several parties, namely: Foundation, Teachers, people and communities. The problems and solutions encountered are: a) The competence of educators. b) Facilities and infrastructure (APE and space or building support).
\end{abstract}

Keywords : Management, Curriculum, Early Childhood Education, and Islamic BoardingSchool

\begin{abstract}
Abstrak
Tujuan dari penelitian ini adalah untuk mengetahui: (1) bagaimana implementasi manajemen kurikulum PAUD di lingkungan Pesantren Al Ittifaqiah. (2) sejauhmana keterlibatan yayasan, guru, orang tua dan masyarakat sekitar dalam mendisain dan merencanakan kurikulum PAUD di lingkungan Pesantren Al Ittifaqiah. (3) problematika apa saja yang dihadapi dalam manajemen kurikulum PAUD di lingkungan Pesantren Al Ittifaqiah. Adapun hasil penelitian ini menunjukkan bahwa implementasi kurikulum PAUD di Pesantren Al Ittifaqiah Indralaya meliputi: (1) Perencanaan, terdiri dari: Program Tahunan (Prota), Program Semester (Prosem), Rencana Kegiatan Mingguan (RKM), dan Rencana Kegiatan Harian (RKH). (2) Pelaksanaan. a) Kegiatan keagamaan, meliputi: Menghafal doa seharihari dan surat-surat pendek, Shalat dhuha, Menonton film kartun religi, Manasik haji, dan Bahasa Arab dasar. b) Pengetahuan umum dan seni, meliputi: Pengenalan rambu-rambu lalu lintas, Membuat alat komunikasi (telepon), dan menari. (3) Pengawasan. a) Pengawasan yayasan ke sekolah, meliputi: Observasi sekolah, Pertemuan kelompok, dan Pembicaraan individual. b) Pengawasan kepala sekolah ke para guru, meliputi: Praktek (demonstrasi)
\end{abstract}


mengajar, Observasi kelas, Pembicaraan individual, dan Pertemuan kelompok. (4) Evaluasi. Dilaksanakan setiap akhir tahun pelajaran dengan model evaluasi CIPP, yang meliputi: context, input (anak, pendidik, dan sarana prasarana), process, dan product. Disain dan perencanaan kurikulum melibatkan beberapa pihak, yaitu: Yayasan, Guru, orang dan masyarakat sekitar. Problematika dalam manajemen kurikulum PAUD di lingkungan pesantren Al Ittifaqiah Indralaya yaitu: a) Kompetensi pendidik. b) Sarana dan prasarana (Alat Permainan Edukatif dan ruang atau gedung penunjang).

Kata kunci: Manajemen, Kurikulum, Anak Usia Dini, dan Pesantren

\section{PENDAHULUAN}

Menjelang usia setengah abad (sejak 10 Juli 1967), Pondok Pesantren Al Ittifaqiah menjadi salah satu diantara dua puluh Pondok Pesantren yang masuk dalam buku "Pesantren-pesantren Berpengaruh di Indonesia". Bersanding dengan beberapa pesantren populer di Indonesia lainnya, yaitu: Pondok Modern Darussalam Gontor, Pondok Pesantren Lirboyo Kediri, Pondok Pesantren Al Amien Prenduan Madura, Pondok Pesantren Tebuireng Jombang dan Pondok Pesantren Darunnajah Ulujami Jakarta (http:/ittifaqiah.ac.id).

Data menjelaskan bahwa Taman Kanak-kanak Islam Al ittifaqiah Indralaya memiliki keunggulan dalam bidang seni Al qur'an. Anak-anak dididik tidak hanya untuk bisa membaca melainkan meghafal dan mengaji beriramah (naghomul qur'an). Sebagaimana dari apa yang penulis amati di lapangan, bahwasanya terdapat beberapa anak yang mampu menghafal beberapa juz di dalam Al qur'an saat duduk di bangku TAKIAH dan bahkan ada juga yang sudah menjadi hafiz/hafizoh cilik, yaitu Fatima Azzahra.

Pesantren sebagai salah satu indikator setiap penyusunan kurikulum sekolah dimasukkan dalam kurikulum sekolah sebagai bentuk upaya menjadikan anak berjiwa santri yang berakhlak mulia. Maka dari itu dari berbagai latar belakang yang penulis jelaskan, penulis tertarik untuk meneliti di Pondok Pesantren Al ittifaqiah Indralaya yang memfokuskan kepada Taman Kanak-kanak Islam Al Ittifaqiah (TAKIAH) untuk menggali dan menganalisa lebih dalam apakah pendidikan yang diterapkan kepada anak usia dini di TAKIAH tersebut didasarkan pendidikan pesantren atau berbasis pesantren.

\section{METODE PENELITIAN}

Penelitian ini menggunakan metode kualitatif dengan pendekatan studi kasus. Pendekatan kualitatif digunakan karena prosedur penelitian yang menghasilkan data deskriptif berupa kata-kata tertulis atau lisan serta perilaku yang diamati dari orang-orang atau sumber informasi. Teknik pengumpulan data adalah wawancara, observasi, dan dokumentasi.

\section{HASIL DAN PEMBAHASAN}

\section{Implementasi Manajemen Kurikulum PAUD di Lingkungan Pesantren}

\section{a. Perencanaan}

Kepala sekolah menyatakan bahwa perencanaan kurikulum berbasis pesantren di TAKIAH dilaksanakan setiap menjelang tahun ajaran baru. Perencanaan kurikulum ini sebagai wujud tindak lanjut hasil evaluasi yang dilaksanakan setiap akhir tahun ajaran. Perencanaan kurikulum ini melibatkan seluruh elemen pesantren yang meliputi Ketua Yayasan Al Ittifaqiah (YALQI), Mudir, Ketua Penjaminan Mutu Pendidikan Al Ittifaiqah, kepala sekolah TAKIAH, guru, orang tua anak, masyarakat sekitar, kepala TU, dan koordinator komite sekolah. 
Pernyataan dari umi Fadila menunjukkan bahwa perencanaan kurikulum PAUD berbasis pesantren di TAKIAH Indralaya dilaksanakan setiap akhir tahun setelah pembagian raport atau hasil perkembangan dari anak didik dengan melibatkan berbagai pihak, baik dari pihak yayasan/sekolah maupun pihak luar yayasan/sekolah (orang tua dan masyarakat).

Disampaikan lebih lanjut bahwa perencanaan kurikulum PAUD berbasis pesantren di TAKIAH Indralaya memang cukup rutin dilaksanakan. Akan tetapi jarang adanya perombakan secara berarti. Perencanaan kurikulum PAUD hanya berkutat membahas pada strategi belajar pada tahun berikutnya, karena terkadang adanya perbedaan dari aspek perkembanngan anak dari tahun sebelumnya. Hala ini sebagaimana disampaikan oleh Umi Fadila: "kita tidak pernah melakukan bongkar muat kurikulum, namun perencanaan kurikulum tetap dilaksanakan biasanya membahas strategi ke depan dengan melihat setiap anak yang mempunyai aspek perkembangan yang berbeda

Perencanaan kegiatan belajar mengajar di TAKIAH Indralaya dibagi atas beberapa langkah kegiatana perencanaanm yang meliputi:

1. Perencanaan Tahunan (Prota)

Format yang digunakan dalam menyusun program tahunan di TAKIAH yaitu dengan kriteria: Tingkat Pencapaian Perkembangan (TPP), indikator, alokasi waktu, nilai-nilai budaya dan karakter, dan nilai kewirausahaan.

2. Perencanaan Semester (Prosem)

Format yang digunakan dalam menyusun program semester di TAKIAH yaitu dengan kriteria: Tema, Lingkup perkembangan, Tingkat Pencapaian Perkembangan (TPP), Indikator, Strategi pembelajaran, Evaluasi, dan Alokasi waktu.

3. Rancangan Kegiatan Mingguan (RKM)

Format yang digunakan dalam menyusun Rancangan Kegiatan Mingguan (RKM) di TAKIAH yaitu dengan kriteria: Lingkup perkembangan, Tujuan Pembelajaran, Strategi pembelajaran, Materi, Alokasi waktu, dan Penilain.

4. Rancangan Kegiatan Harian (RKH)

Format yang digunakan dalam menyusun Rancangan Kegiatan Harian (RKH) di TAKIAH yaitu dengan kriteria: Hari/Tanggal, Indikator, Kegiatan, Sumber belajar, dan Penilaian (Strategi Pembelajaran dan Perkembangan Anak).

\section{b. Pelaksanaan}

Dalam pelaksanaan kurikulum, kegiatan belajar mengajar berdasarkan RKH yang telah dibuat di TAKIAH Indralaya, guru mengatur kelas sedemikian rupa sehingga kegiatan dapat dilaksanakan secara berkelompok (kecil) maupun perorangan. Guru memberikan kebebasan kepada anak untuk memilih media belajar yang mereka gemari sesuai minatnya masing-masing.

Hal ini senada dengan apa yang dijelaskan oleh salah satu guru kelas saat diwawancari bahwa proses belajar mengajar di TAKIAH biasanya dengan membagi anak ke berbagai kelompok yang sesuai dengan warna meja di dalam kelas, seperti warna biru, merah dan hijau.

Pelaksanaan kurikulum PAUD berbasis pesantren di TAKIAH Indralaya terdiri dari berbagai kegiatan keagamaan yang diimbangi dengan kegiatan sains dan ilmu pengetahuan sebagai berikut:

\section{Kegiatan Keagamaan di TAKIAH}

a) Menghafal dan memuraja'ah doa sehari-hari dan surat-surat pendek

Menghafal doa sehari-hari dan surat-surat pendek di TAKIAH Indralaya biasanya dilaksanakan saat berbaris di depan kelas dan dilanjutan di dalam kelas. Adapun 
pelaksaannya sambil bermain dan tidak memaksa dengan masih mengedepankan minat dari masing-masing anak.

Kegiatan menghafal ayat suci Al Qur'an di TAKIAH selain pada jam formal yang tersusun di dalam RKH ada juga kegitan ekstrakulikulernya yang dilaksanakan pada sore hari yang di ketuai oleh Ustad Zaimuddin, M.S.I, Alhafizh., kegiatan ini dinamai dengan Madrasah Tahfizul Qur'an Lil Athfal Al ittifaqiah (MASTAQIAH).

Sebagaimana disampaikan oleh ketua yayasan pondok pesantren Al ittifaqiah Indralaya bahwa pondok pesantren Al Ittifaqiah ini terkenal dengan mendali-mendalinya dalam bidang seni Al Qur'an. Baik itu seni menghafal, tilawah, dan kaligrafi. Tidak terkecuali di TAKIAH nya sendiri. TAKIAH memiliki program ekskul atau program unggulan dalam bidang seni Al Qur'an juga. Anak-anak dididik di bawah naungan MASTAQIAH, guna menumbuhkan minat menghafal sejak dini.

MASTAQIAH merupakan program unggulan yang menaungi anak-anak yang berusia 5-12 tahun (Usia TK dan MI), dilaksanakan pada sore hari sekitar pukul 16.3017.00 WIB santri menyetorkan hafalan yang mereka sudah hafalkan dan pada pukul 17.00-17.30 santri bersama-sama mengulangi hafalan atau mentaqrir hafalan secara murottal.

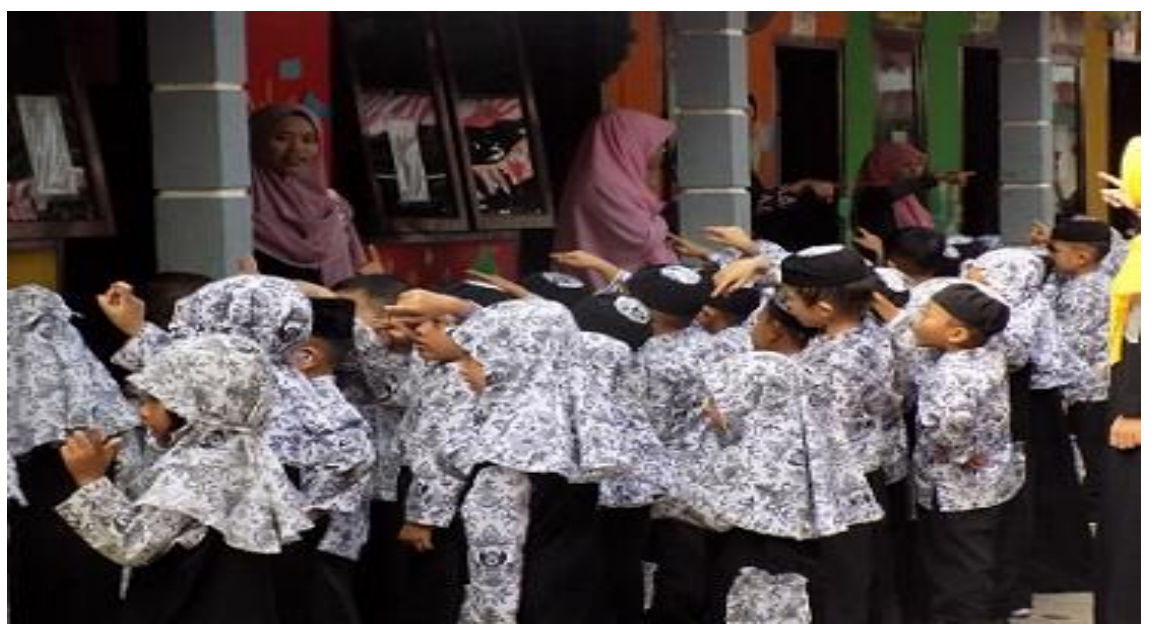

Gambar 1 Mengulangi hafalan doa sehari-hari dan surat-surat pendek

\section{b) Shalat Dhuha}

Sejak dini anak harus diperkenalkan dengan shalat. Orang tua dan guru harus terlibat aktif dalam melatih anak rajin shalat dan berdoa, agar mentalitas spiritual terbentuk dengan kokoh.

Di TAKIAH Indralaya pembiasaan shalat dhuha setiap pagi dilaksanakan ketika anak-anak masuk kelas. Mereka shalat dhuha berjamaah yang diimami dari salah satu anak laki-laki yang gagah dan rapinya dengan menggunakan kopiah.

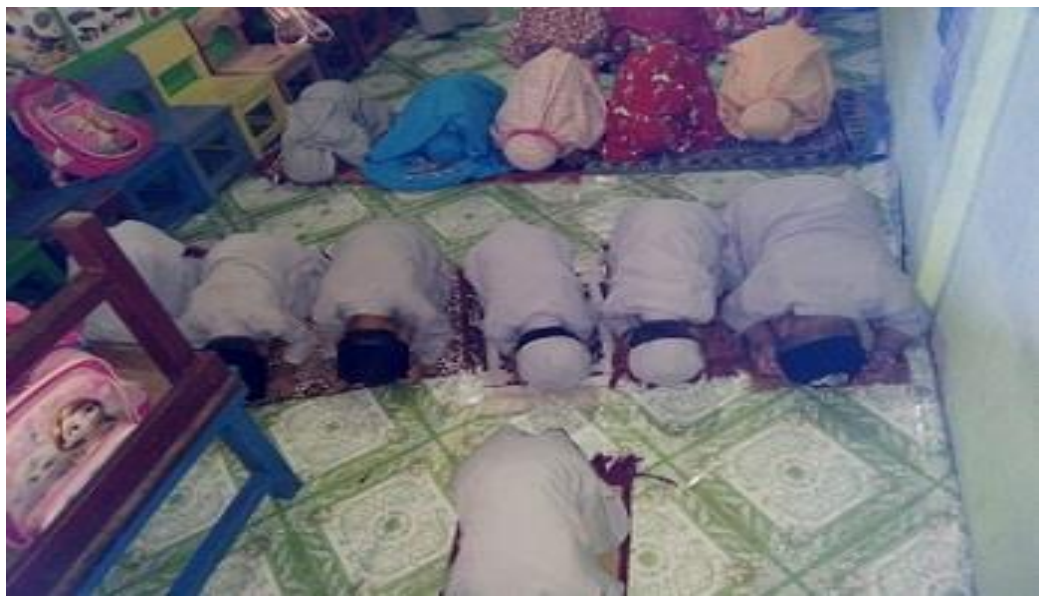


Gambar 2 Pelaksaan shalat dhuha berjamaah di dalam kelas

\section{c) Menonton Film Kartun Religi}

Dunia anak adalah dunia bermain. Mereka biasanya suka dengan berbagai macam warna-warna, bentuk, maupun rupa. Tak terkecuali film-film kartun. Seperti film-film yang biasa tayang di televisi; Upin dan Ipin, Tom and Jerry, Pada Zaman Dahulu, dll. Namun sebagai orag tua dan guru harus tetap mengawasi dan mengontrol durasi dari apa yang mereka tonton.

TAKIAH Indralaya memanfaat teknologi untuk anak-anak dengan menayangkan film kartun religi dalam seminggu sekali setiap kelasnya. Anak-anak sangat antusias dan berperan aktif dalam pelaksaan kegiatan menonton film religi ini, dengan berbagai ekspresi yang mereka tuangkan saat menyaksikan film yang mereka tunggu-tunggu.

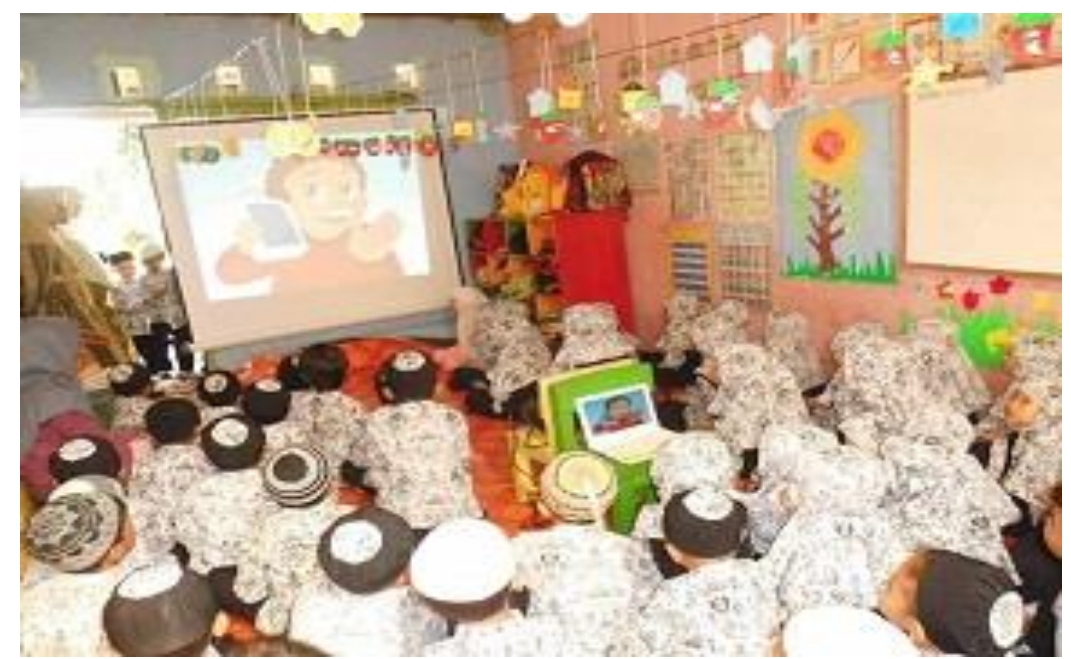

d) Manasik Haji

Gambar 3 Kegiatan menonton film dengan LCD Proyektor

Pelaksanaan pembelajaran yang biasanya dilakukan saat mendekati hari raya idul adha atau lebih kenal dengan sebutan hari raya kurban di TAKIAH Indralaya ialah manasik haji. Kegiatan ini biasanya dilakukan sebelum menjelang hari raya tersebut yang melibatkan dari berbagai pihak. Baik itu Yayasan Al ittifaqiah, para guru TAKIAH, dan bahkan orang tua anak.

Kegiatan manasik haji selain untuk seremonial penyambutan hari raya idul adha, ia juga merupakan kegiatan yang mampu mengenalkan kepada anak sejak dini apa itu kakbah, melontar jumroh, lari kecil sofa warwah, dan lain sebagainya.

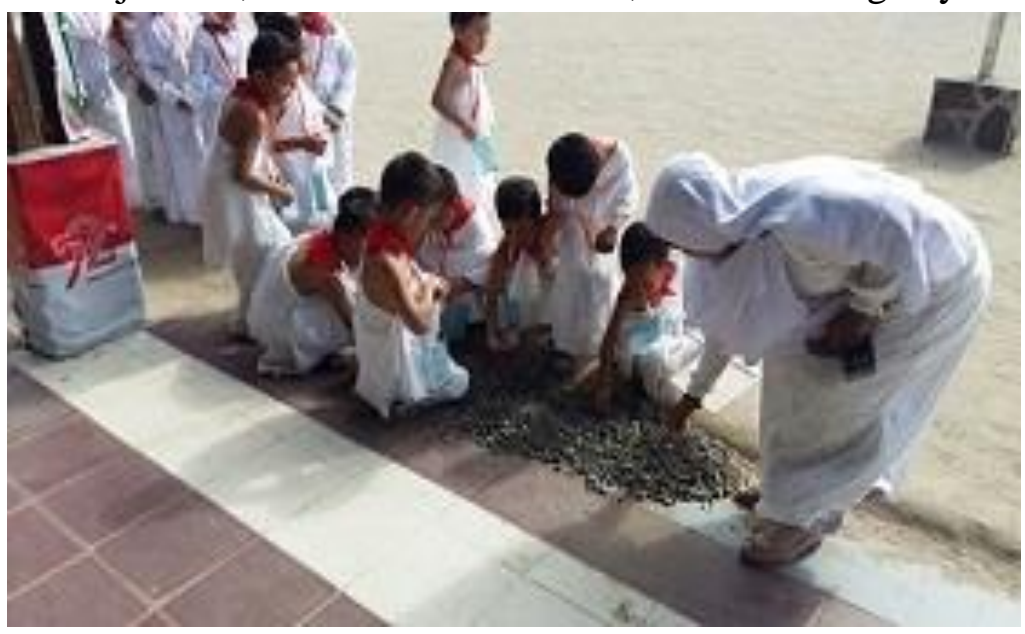


Gambar 4 Kepala sekolah mengajak dan mengarahkan anak untuk mengambil beberapa bebatuan kecil guna melontar jumroh

\section{e) Bahasa Arab Dasar}

Bahasa merupakan alat komunikasi yang bersifat universal, yang artinya hampir tidak ada seorang pun yang tidak berkomunikasi melalui bahasa. Bahasa itu sendiri meliputi berbicara, menulis, dan membaca.

Salah satu aspek perkembangan anak yang dilaksanakan di TAKIAH Indralaya yang harus dikembangkan yaitu aspek perkembangan bahasa anak. Jika dihubungkan dengan pelaksanaan kurikulum berbasis pesantren, maka kegiatan bahasa di TAKIAH ialah bahasa Arab (menulis, membaca, dan berbicara).

2. Pengetahuan Umum dan Seni

a) Pengenalan Rambu-rambu Lalu Lintas

Pengenalan rambu-rambu lalu lintas kepada anak di TAKIAH Indralaya dilaksanakan bekerja sama dengan polsek Indralaya yang tidak jauh dari sekolah TAKIAH itu sendiri. Pengenalan ini bertujuan agar anak mengenal rambu-rambu lalu lintas dan cara menyemberang jalan dengan baik dan benar, mengingat Indralaya yang berada di tepi jalan raya lintas timur.

Kepala sekolah TAKIAH Indralaya menuturkan bahwa pelaksanaan kegiatan pengenalan rambu-rambu lalu lintas merupakan kegiatan tahunan di TAKIAH. Hal ini bertujuan agar anak bisa mengetahui maksud dan tujuan dari rambu-rambu lalu lintas yang sering meraka lihat setiap harinya.

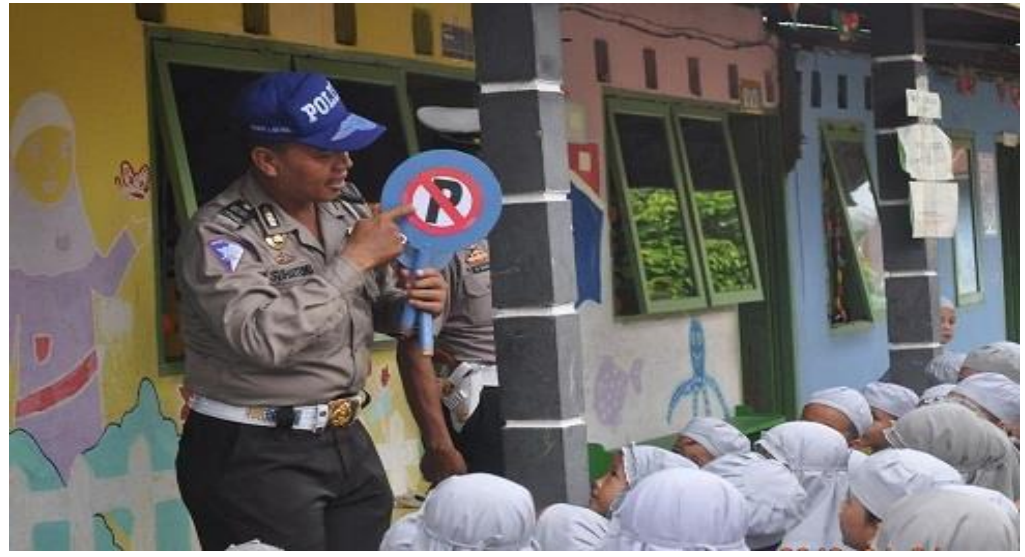

Gambar 5 Bapak polisi menjelaskan tanda dilarang parkir

b) Membuat alat komunikasi (telepon)

Kegiatan membuat alat komunikasi (telepon) merupakan implementasi dari Rancangan Kegiatan Harian (RKH) yang mampu menstimulus dan mengembangkan berbagai aspek perkembangan anak, dari aspek perkembangan kognitif, psikomotorik (halus), sosial emosional, bahasa, dan seni. Pemanfaatan bahan bekas (kardus) mengajarkan kepada anak didik untuk berfikir kreatif dan inovatif. Sehingga kelak dewasa mampu memanfaatkan segala sesuatu dari bahan bekas untuk dijadikan sesuatu yang berguna, baik untuk diri sendiri maupun orang lain.

c) Menari

Kegiatan menari merupakan stimulus perkembagan fisik motorik bagi anak usia dini, baik itu motorik halus maupun kasar. Seperti gerakan jari jemari, maju mundur, lompat-lompat, dan bahkan lari-lari kecil. Namun tidak hanya aspek perkembangan fisik motorik saja, seni menari juga mampu menstimulus berbagai aspek perkembangan yang lainnya; perkembangan kognitif, sosial emosional,dan bahasa. 
Kegiatan menari di TAKIAH merupakan implementasi dari RKH yang dibuat dan disusun oleh guru. Kegiatan ini mengajarkan kepada anak sejak dini tentang taritarian tradisional, khususnya tarian tradisonal Sumatera Selatan.

\section{c. Pengawasan}

1. Pengawasan dari Yayasan ke Sekolah

a) Observasi Sekolah

Pengawasan langsung dilakukan yayasan dengan waktu yang tidak terduga dan kondisional. Pengawasan dengan teknik ini dilakukan oleh ketua penjaminan mutu pendidikan Al ittifaqiah dengan mendatangi langsung ke sekolah untuk mengawasi hal-hal yang terkait dengan mutu pendidikan TAKIAH.

b) Pertemuan Kelompok

Pertemuan kelompok biasanya berupa rapat bulanan yang dilaksanakan setiap hari Jum'at pada minggu pertama di awal bulan yang bertempat di kampus utama pondok pesantren $\mathrm{Al}$ ittifaqiah Indralaya yang dihadiri para gurudan karyawan dari tingkat Taman Kanak-kanak Islam (TKI), Madrasah Ibtidaiyah (MI), Madrasah Tsanawiyah (Mts), Madrasah Aliyah (MA), dan Perguruan Tinggi (PT).

c) Pembicaraan Individual

Pengawasan atau monitoring kurikulum PAUD dengan teknik ini dilaksanakan untuk mengawasi, mengontrol, dan membimbing kepala sekolah dan guru-guru yang berhubungan dengan masalah di TAKIAH.

2. Pengawasan Kepala Sekolah ke Para Guru

a) Praktek (demonstrasi) mengajar

Pengawasan dengan teknik ini, biasanya sering digunakan untuk guru baru, sedangkan untuk guru yang sudah lama mengajar di TAKIAH Indralaya jarang sekali digunakan karena dianggap sudah hafal dengan ciri khas kurikulum PAUD di TAKIAH.

b) Observasi Kelas

Pengawasan atau monitoring kurikulum PAUD dengan teknik ini dilaksanakan oleh kepala sekolah TAKIAH dengan mendatangi langsung setiap kelas untuk mengawasi problem-problem yang berhubungan dengan proses belajar mengajar.

c) Pembicaraan Individual

Pengawasan atau monitoring kurikulum PAUD dengan teknik ini dilaksanakan untuk mengawasi, mengontrol, dan membimbing guru-guru TAKIAH Indralaya dengan cara face to face.

d) Pertemuan Kelompok

Pertemuan kelompok ini berupa rapat bulanan yang biasanya dilaksanakan setiap awal bulan yang bertempat di TAKIAH Indralaya.

Pengawasan atau monitoring terkait pelaksanaan kurikulum di lingkungan pesantren juga dilakukan oleh para orang tua anak. Hal ini merupakan hasil dari apa yang penulis amati secara langsung di lapangan. Para orang tua anak bahkan tidak sungkan-sungkan untuk mengawasi anaknya yang sedang bermain di dalam kelas maupun di luar kelas. Penulis berpendapat bahwasanya dengan adanya pengawasan dari orang tua yang seperti ini setidaknya mampu membantu kepala sekolah dalam mengawasi gerak-gerik guru yang kurang disipilin dalam megajar.

\section{d. Evaluasi}

Untuk mengevaluasi kurikulum PAUD di lingkungan pesantren di TAKIAH Indralaya dalam hal ini digunakan model CIPP, yang meliputi empat aspek yang nantinya 
dijadikan sasaran evaluasi kurikulum PAUD, yaitu: context, input, process, dan output. Secara spesifik keempat aspek tersebut antara lain sebagai berikut:

1. Context (konteks)

Berbicara masalah konteks TAKIAH Indralaya, maka tidak dapat dipisahkan lagi dari basic-nya, yaitu pesantren Al ittifaqiah. Sistem pendidikan dan pengajaran yang digunakan sekolah ini menggunakan kurikulum dari dinas yang dikolaborasikan dengan kurikulum pesantren, yang bercorak Qur'ani.

Selain secara corak atau latar belakang pesantrennya, implementasi kurikulum PAUD berbasis pesantren di TAKIAH Indralaya juga sesuai dengan letak strategis sekolah (TK) di area pesantren Al Ittifaqiah dan lingkungan kabupaten ogan ilir yang dijuluki kota santri. Hal ini membuktikan penerapan kurikulum PAUD di lingkungan pesantren di TAKIAH Indralaya didukung oleh background pesantren dan letak strategis pesantren. 


\section{Input (masukan)}

Input yang mendukung kurikulum PAUD di lingkungan pesantren $\mathrm{Al}$ ittifaqiah terdiri dari tiga jenis antara lain anak (peserta didik), guru/pendidik, dan sarana prsarana. 3. Process (proses)

Proses pembelajaran di TAKIAH Indralaya dilaksanakan pada pukul 08.00-11.00 WIB. Sebelum proses belajar dimulai di dalam ruangan, anak-anak terlebih dahulu dibiasakan untuk bernyanyi, menghafal doa sehari-hari, dan surat pendek di depan kelas. Setelah itu mengambil wudhu untuk persiapan shalat dhuha di kelas masing-masing yang didampingi oleh guru. Pelaksanaan kurikulum di TAKIAH tidak dapat dipisahkan dengan karakteristik pesantren, karena TAKIAH dibawah naungan pesantren Al ittifaqiah.

4. Product (hasil)

Hasil dari penerapan kurikulum PAUD di lingkungan pesantren di TAKIAH Indralaya terlihat pada kompetensi anak (peserta didik). Kompetensi anak-anak TAKIAH terutama dalam aspek perkembangan moral agama, bahasa Arab dasar, dan seni Al Qur'an yang relatif lebih mumpuni dibanding dengan Taman Kanak-kanak yang tidak menerapkan sistem kurikulum PAUD berbasis pesantren. Produk dari kurikulum berbasis pesantren di TAKIAH Indralaya sebenarnya diarahkan agar anak memiliki perkembangan yang optimal dalam aspek berbahasa Arab, bermoral, dan berjiwa Qur'ani.

\section{Keterlibatan Yayasan, Guru, Orang Tua, dan Masyarakat Sekitar dalam Mendesain} dan Merencanakan Kurikulum PAUD di TAKIAH

\section{a. Yayasan}

Yayasan Al Ittifaqiah Indralaya (YALQI) sangat terlibatan dalam mendisain dan merencanakan kurikulum PAUD di TAKIAH Indralaya, karena TAKIAH memang berada di bawah naungan yayasan Al Ittifaqiah.

"Iyo memang ado dek dalam perencanaan dan bentuk kurikulum di TAKIAH ini keterlibatan dari pihak YALQI. Kan TAKIAH kito ini didirikan oleh YALQI dan memang kurikulumnyo tu gabongan dari kurikulum diknas dengan kurikulum pesantren."

Hal ini senada dengan apa yang disampikan oleh Ibu Muyasaroh saat diwawancarai bahwa kurikulum di PPI ini menggunakan kurikulum berjenjang, yaitu kurikulum yang berkelanjutan dari jenjang pendidikan Taman Kanak-kanak, MI, Mts, MA, dan Perguruan Tinggi. Semuanya memiliki ciri khas Al Qur'an, karena memang di pesantren ini pendidikannya bercorak Al Qur'an, baik dari seni menghafal, naghom, dan Kaligrafi. Sedangkan untuk anak-anak MI dan TAKIAH sendiri ada program MASTAQIAH, yaitu Madrasah Tahfizul Qur'an Lil Atfal Al Ittifaqiah.

\section{b. Guru}

Selain keterlibatan yayasan dalam mendisain dan merencanakan kurikulum PAUD di lingkungan pesantren di TAKIAH Indralaya, guru pun memiliki peran yang sangat penting karena memang selain merencanakan kurikulum, guru merupakan implementator kurikulum itu sendiri.

Guru merupakan pelaksana kurikulum haruslah memiliki kompetensi yang baik agar anak didik bisa dibimbing dan diarahkan sesuai dengan visi, misi, dan tujuan sekolah itu sendiri. Dalam merencakan suatu proses pembelajaran di TAKIAH Indralaya biasanya dimuat dalam suatu bentuk acuan yang berbentuk pedoman kurikulum, baik itu program tahunan, semester, mingguan, dan harian. Guru dituntut mampu membuat program harian (RKH) yang kreatif dan inovatif agar semua aspek perkembangan anak mampu berkembang dengan maksimal. 


\section{c. Orang Tua dan Masyarakat Sekitar}

Salah satu subtansi penting manajemen kurikulum yaitu partisipasi orang tua dan masyarakat dalam pendidikan. Hubungan lembaga pendidikan dengan orang tua dan masyarakat adalah suatu proses komunikasi antara lembaga pendidikan dengan orang tua dan masyarakat dengan tujuan untuk meningkatkan pemahaman orang tua dan masyarakat terhadap kebutuhan dan praktik pendidikan yang pada ahirnya bekerja sama untuk meningkatkan kualitas pendidikan di suatu lembaga pendidikan.

Guru harus mampu bekerja sama dengan orang tua masing-masing anak. Guru mengajak orang tua anak untuk datang ke sekolah dan memberikan kesempatan kepada mereka untuk mengamati anaknya. Atau, guru dapat pergi bersama dengan orang tua pada saat perjalanan lapangan sesuai program TK-nya. Pada saat itu guru mengambil kesempatan untuk berbicara dengan orang tua anak untuk membahas perkembangan anak atau masalah-masalah khusus yang dihadapi anak. Bahkan guru dapat meminta orang tua setiap anak untuk mengamati perkembangan anak di rumahnya.

Selain keterlibatan dari yayasan dan guru, orang tua anak juga terlibat dalam merencanakan kurikulum PAUD berbasis pesantren di TAKIAH Indralaya yang biasanya dilaksanakan sebelum tahun ajaran baru. Kegiatan perencanaan kurikulum PAUD berbasis pesantren di TAKIAH Indralaya berbentuk rapat yang dilaksanakan di masjid pondok pesantren $\mathrm{Al}$ ittifaqiah.

\section{Problematika Manajemen Kurikulum PAUD Berbasis Pesantren di TAKIAH}

\section{a. Kompetensi Pendidik}

Idealnya pendidik PAUD profesional adalah pendidik PAUD yang memiliki empat kompetensi, yaitu kompetensi pedagogik, kompetensi kepribadian, kompetensi sosial, dan kompetensi profesional. Selain itu juga pendidik PAUD profesional harus memiliki sertifikat pendidik melalui sertifikasi pendidik dan aktif dalam forum organisasi Himpunan Pendidik Anak Usia Dini (HIMPAUDI), Ikatan Guru Taman Kanak-kanak (IGTK), maupun Ikatan Guru Raudhatul Athfal (IGRA).

Masalah pendidik yang kurang berkompeten dan profesional di TAKIAH Indralaya cukup sedikit, karena memang kebanyakan guru di TAKIAH sudah berijazah S1 PAUD dan pihak yayasan telah memberi beasiswa kepada beberapa guru yang masih belum berijazah S1 untuk kuliah di berbagai kampus seperti Universitas Terbuka (UT), Universitas Islam Negeri Raden Fatah Palembang (UIN RAFA), dan Sekolah Tinggi Ilmu Tarbiyah Al Qur'an Al ittifaqiah (STITQI) sendiri yang notabennya masih di bawah naungan yayasan $\mathrm{Al}$ ittifaqiah. Namun untuk keaktifan dalam organisasi hanya kepala sekolah dan beberapa guru yang aktif di berbagai ikatan guru yang ada di kabupaten Ogan Ilir.

Terdapat beberapa guru di TAKIAH Indralaya yang belum berkompeten dari berbagai hal, seperti belum disiplin dalam membuat $\mathrm{RKH}$, kurang berkarakter, dan masih kurangnya rasa keibuan kepada anak. Di sini peran yayasan dan kepala sekolah sangat penting untuk terus mengawasi dan mengevaluasi guru-guru yang masih belum bekerja secara maksimal atau setengah hati. Khususnya kepala sekolah yang secara langsung bisa mengamati pelaksanaan pembelajaran setiap harinya agar kelak guru-guru di TAKIAH bisa menjadi guru yang profesional dan berkompeten dalam merencanakan, melaksanakan, dan mengevaluasi kurikulum PAUD di lingkungan pesantren Al Ittifaqiah Indralaya. 


\section{b. Sarana dan Prasarana}

\section{Alat permainan edukatif}

Alat Permaianan Edukatif (APE) di TAKIAH Indralaya masih sangat kurang, baik itu permainan indoor maupun outdoor. Ditambah lagi masih terdapat beberapa guru yang belum kreatif dan inovatif dalam membuat alat permainan edukatif bagi anak-anak di TAKIAH Indralaya. Ini merupakan masalah yang cukup besar sebenarnya, mengingat guru yang merupakan implementator kurikulum seharusnya mampu melaksanakan tugasnya dengan baik agar permasalahan ini tidak berlanjut.

Di sini peran kepala sekolah harus benar-benar dominan, karena jika hal semacam ini terus berlanjut maka perkembangan anak tidak akan mampu berkembang dengan maksimal dan juga dapat menurunkan minat orang tua untuk menyekolahkan anaknya di TAKIAH. Selain itu Yayasan Al ittifaqiah (YALQI) selaku penopang utama dari TAKIAH ini harus mampu mengawasi dan mengevaluasi guru-guru yang memang sebagai pelaksana dari pembelajaran dan yayasan pun harus segera melengkapi atau memperbaiki alat permainan yang ada di TAKIAH, mengingat setelah penulis amati secara langsung terdapat beberapa alat permainan dalam kondisi yang tidak sempurna, meskipun memang masih layak pakai.

Selain itu guru-guru di TAKIAH yang belum mampu membuat Alat Permainan Edukatif (APE) agar bisa diikutsertakan dalam pelatihan-pelatihan dan jika perlu TAKIAH sendiri yang mengadakan pelatihan secara khusus untuk mewadahi guru-guru yang belum mampu membuat alat permainan edukatif tersebut.

\section{Ruang atau gedung penunjang}

Di Taman Kanak-kanak Islam Al ittifaqiah (TAKIAH) Indralaya masih kekurangan beberapa ruangan atau gedung penunjang seperti, masih bergabungnya ruang kepala sekolah dengan guru, belum ada ruang perpustakaan khusus, Usaha Kesehatan Sekolah yang dilengkapi dengan P3K, dan ruang/gedung pertemuan untuk rapat.

Hal yang semacam ini merupakan masalah yang harus segera diselesaikan oleh pihak sekolah (TAKIAH), terutama pihak yayasan Al ittifaqiah (YALQI), mengingat dari beberapa kekurangan di atas akan dapat mempengaruhi kualitas sekolah dan berdampak pada penurunan minat orang tua untuk menyekolahkan anaknya di TAKIAH.

Solusinya adalah YALQI dan TAKIAH harus segera mengevaluasi permasalahan ini dengan cepat dan sigap. Hal ini pun sebenarnya sudah disampaikan oleh kepala sekolah TAKIAH saat diwawancarai, "sarana dan prasarana di TAKIAH memang masih kurang, baik dari sarana bermain anak (indoor dan outdoor) dan sarana penunjang sekolah seperti gedung pertemuan, UKS, dan Perpustakaan. Namun sebenarnya kami dari pihak sekolah sudah mengajukan proposal kepada pihak yayasan Al ittifaqiah Indralaya, hanya saja kami masih menunggu keputusan dari yayasan."

\section{KESIMPULAN}

1. Implementasi Manajemen Kurikulum PAUD di lingkungan Pesantren Al Ittifaqiah

Manajemen kurikulum PAUD di TAKIAH terdiri dari berbagai implementasi, yaitu; perencanaan, pelaksanaan, pengawasan, dan evaluasi. Kesemuanya itu memiliki kekhasan pesantren terutama kekhasan Qur'annya (menghafal, naghom, dan kaligrafi) yang memang merupakan keunggulan dari TAKIAH itu sendiri.

Perencanaan kurikulum PAUD di TAKIAH terdiri dari Program tahunan, Program semester, Rancangan Kegiatan Mingguan, dan Rancangan Kegiatan Harian. Sedangkan pelaksanaan kurikulum di TAKIAH didominasi dengan berbagai macam kegiatan keagamaan, yaitu menghafal doa sehari-hari dan ayat suci Al qur;an, shalat dhuha, manasik haji, menonton film kartun religi, dan bahasa Arab dasar. kegiatan 
keagamaan tersebut juga didukung dengan kegiatan seni, sains, dan ilmu pengetahuan umum.

Pengawasan kurikulum di TAKIAH dilakukan oleh pihak yayasan dan kepala sekolah. Yayasan langsung mengawasi ke sekolah dengan berbagai macam teknik, yaitu observasi ke sekolah, pertemuan kelompok, pembicaraan individu (Kepsek dan guru). Sedangkan Pengawasan Kepala Sekolah ke Para guru meliputi Praktek (demonstrasi) mengajar, Observasi Kelas, Pembicaraan Individual, Pertemuan Kelompok. Pengawasan pelaksanaan kurikulum PAUD berbasis pesantren di TAKIAH juga dilakukan oleh orang tua anak. Para orang tua anak bahkan tidak sungkan-sungkan untuk mengawasi anaknya yang sedang bermain di dalam kelas maupun di luar kelas.

Untuk mengevaluasi kurikulum PAUD di TAKIAH Indralaya menggunakan model CIPP, yang meliputi empat aspek yang bisa dijadikan sasaran evaluasi kurikulum PAUD, yaitu: Context, Input (Anak, pendidik, dan sarana prasarana), Process, dan Product.

2. Keterlibatan Yayasan, Guru, Orang Tua dan Masyarakat Sekitar dalam Perencanaan Kurikulum PAUD di TAKIAH

Yayasan, Guru, Orang Tua, dan Masyarakat Sekitar memiliki keterlibatan yang cukup kuat dalam perencanan kurikulum PAUD berbasis pesantren di TAKIAH. Mereka mempunyai peranan dan fungsinya masing-masing dalam manajemen kurikulum PAUD. Yayasan sebagai induk dan pendiri berperan dalam pendanaan dan kelengkapan sarana dan prasarana. Guru yang merupakan implementator kurikulum itu sendiri berperan dalam membuat dan merancang kegiatan harian yang akan dijadikan sebagai pedoman pembelajaran. Sedangkan orang tua dan masyarakat sekitar dilibatkan dalam rapat awal tahun dan ahir tahun yang berperan sebagai informan awal terkait dengan kondisi anak.

Dengan adanya keterlibatan dari berbagai pihak tersebut membuat manajemen kurikulum PAUD di TAKIAH terkontrol dengan cukup baik.

3. Problematika Manajemen Kurikulum PAUD di TAKIAH

Problematika dalam pengelolaan kurikulum PAUD di TAKIAH yaitu, kurang berkompeten dan profesionalnya pendidik, serta sarana prasarana yang belum memadai, baik itu Alat Permainan Edukatif (APE) maupun gedung penunjang (ruang belajar dan rapat). Namun secara keseluruhan problematika manajemen kurikulum PAUD di TAKIAH terkelola dengan baik, terbukti dengan adanya kepedulian dari yayasan dengan mengadakan beasiswa bagi guru yang belum berijazah sarjana dan melibatkan beberapa guru untuk bergabung dengan ikatan-ikatan guru PAUD di Ogan Ilir. Sedangkan untuk beberpa gedung penunjang sedang proses pembangunan.

Penulis akhiri dengan sebuah kalimat, "Jika di dalam Islam Al Qur'an merupakan kitab suci atau pedoman bagi umatnya, maka Kurikulum merupakan pedoman atau kitab suci bagi umatnya pula (pendidik)". 


\section{DAFTAR PUSTAKA}

Agus Zainul Fitri, Manajemen Kurikulum Pendidikan Islam dari Normatif-Filosofis ke Praktis, Bandung: Alfabeta, 2013

Dirjen Pendidikan Islam Kemenag RI, Panduan Teknis Pengembangan Kurikulum Madrasah Aliyah; Dokumen Utama, Jakarta: Kemenag RI, 2010

Haidar Putra Daulay, Historitas dan Eksistensi Pesantren, Sekolah dan Madrasah, Yogyakarta: Tiara Wacana, 2004

H.E Mulyasa, Kurikulum Tingkat Satuan Pendidikan, Cet. I, Bandung: Remaja Rosdakarya, 2006

Husain Yasin, Asas al-idarah al-tarbawiyyah wa al-madrasiyyah wa al-isyraf al-tarbawiy, Dar al-Fikr, 2009

Jamal Ma'mun Asmani, Manajemen Strategi Pendidikan Anak Usia Dini, Memahami Sistem Kelembagaan, Metode Pengajaran, Kurikulum, Keterampilan dan Pelatihanpelatihannya, Yogyakarta: Diva Press, 2009

Khaeruddin, Mahfud Junaedi, Kurikulum Tingkat Satuan Pendidikan Konsep dan Implementasi Masyarakat, Cet. II, Yogyakarta: Pilar Mandiri, 2007

Maimunah Hasan, PAUD (Pendidikan Anak Usia Dini), Yogyakarta: Diva Press, 2009

Manullang, Dasar-dasar Manajemen, Yogyakarta: UGM Press, 2012

Mujamil Qomar, Pesantren dari Transformasi Metodologi Menuju Demokratisasi Institusi, Jakarta: Erlanggga, 2005

Peraturan Menteri Pendidikan dan Kebudayaan Republik Indonesia Nomor 146 tahun 2014 tentang kurikulum 2013 pendidikan anak usia dini, Jakarta, 2014

R. Ibrahim dan Mohammad Ali, "Teori Evaluasi Pendidikan", dalam Mohammad Ali, dkk., Ilmu dan Aplikasi Pendidikan: Bagian II, Ilmu Pendidikan Praktis, Bandung: Imtima, 2009

Sandra H. Petersen dan Donna S. Wittmer, Kurikulum Pendidikan Anak Usia Dini Berbasis Pendekatan Antar Personal (a Relationship-Based Approach), terj. Arief Rakhman, Jakarta: prenada Media Group, 2015

Soemartin Pramonodawo, Pendidikan Anak Prasekolah,Cet. II, Jakarta: Rineka Cipta, 2003

Teguh Triwiyanto, Manajemen Kurikulum dan Pembelajaran, Jakarta: Bumi Aksara, 2015

Tohirin, Metode Penelitian Kualitatif dalam Pendidikan dan Bimbingan Konseling, Jakarta: RajaGrafindo Persada, 2012

Umiarso dan Nur Zazin, Pesantren di Tengah Arus Mutu Pendidikan: Menjawab Problematika Kontemporer Manajemen Mutu Pesantren, Semarang: Rasail, 2011

Undang-undang RI No. 20 tahun 2003 Tentang Sistem Pendidikan Nasional. 
Islamic EduKids: Jurnal Pendidikan Anak Usia Dini

Homepage: https://journal.uinmataram.ac.id/index.php/IEK/index

Vol. 01 No. 02, Desember 2019

P-ISSN:

E-ISSN:

Zamakhsari Dhofier, Tradisi Pesantren: Studi tentang Pandangan Hidup Kyai dan Visinya Mengenai Masa Depan Indonesia, Jakarta: LP3ES, 2011 